\title{
Disruption of Decrements in Conditioned Stimulus Processing by Selective Removal of Hippocampal Cholinergic Input
}

\author{
Mark G. Baxter, ${ }^{1}$ Peter C. Holland, ${ }^{3}$ and Michela Gallagher ${ }^{2}$ \\ ${ }^{1}$ Curriculum in Neurobiology and ${ }^{2}$ Department of Psychology, University of North Carolina, Chapel Hill, North Carolina \\ 27599, and ${ }^{3}$ Department of Psychology: Experimental, Duke University, Durham, North Carolina 27708
}

The attention directed to environmental stimuli can be modified by experience. For example, preexposure of a conditioned stimulus (CS) in the absence of reinforcement can retard subsequent conditioning of that stimulus when it is paired directly with an unconditioned stimulus, a phenomenon referred to as latent inhibition. Similarly, consistent pairings of a CS with another event can slow the acquisition of new information about that CS. Such phenomena suggest that reductions in the processing of CSs occur when they are made behaviorally irrelevant or consistent predictors of other events. On the basis of the observation that hippocampal lesions prevented such reductions in CS processing, we hypothesized that damage to basal forebrain cholinergic neurons that project to the hippocampus, using microinjections of the selective immunotoxin 192 lgG-saporin into the medial septum/vertical limb of the diagonal band (MS/VDB), also would disrupt normal reductions in CS processing. Lesions of hippocampal cholinergic input disrupted decreases in CS processing, manifested in both an absence of latent inhibition and a lack of reduced processing of a CS that had been a consistent predictor of another CS. These results indicate that cholinergic neurons in the MS/NDB play a role in the regulation of CS processing. Furthermore, these findings (in conjunction with previous findings) implicate both rostral (hippocampal-projecting) and caudal (corticalprojecting) regions of the basal forebrain cholinergic system in the modulation of attention.

Key words: medial septum; acetylcholine; cholinergic basal forebrain; 192 IgG-saporin; immunotoxin; classical conditioning; attention; associative learning; latent inhibition; Alzheimer's disease
The rat basal forebrain contains neurons that provide the major source of cholinergic innervation to the hippocampus, neocortex, and amygdala (Wainer and Mesulam, 1990). The specific role of these neurons in cognitive function has been difficult to determine in the absence of lesion techniques specific to cholinergic neurons that spare noncholinergic basal forebrain neurons. On the basis of the effects of nonselective neurotoxic and electrolytic lesions of basal forebrain nuclei, distinct functions have been proposed for cholinergic projections to the neocortex and hippocampus. The cholinergic neurons that project to neocortex are thought to be involved primarily in the regulation of attentional function (Robbins et al., 1989; Muir et al., 1992, 1994; Voytko et al., 1994), whereas cholinergic basal forebrain neurons projecting to the hippocampus are thought to play an important role in learning and memory (Hagan et al., 1988; Kelsey and Landry, 1988; Decker et al., 1992; Kelsey and Vargas, 1993).

The development of 192 IgG-saporin, an immunotoxin that selectively destroys cholinergic basal forebrain neurons after sitespecific injections into the basal forebrain (Wiley et al., 1991; Heckers et al., 1994), has made possible direct experimental investigation of the role of these neurons in cognitive function. Attentional disruption produced by nonselective neurotoxic basal

\footnotetext{
Received Jan. 30, 1997; revised April 14, 1997; accepted April 16, 1997.

This research was supported by National Institutes of Health (Grants P01AG09973 and K05-MH01149 to M.G. and R01-MH53667 to P.C.H.), by the Human Frontier Science Research Program (to M.G. and P.C.H.), and by a National Science Foundation Predoctoral Fellowship (to M.G.B.). We thank J. Chen, P. N. Fielder, and L. K. Gorman for technical assistance.

Correspondence should be addressed to Dr. Mark G. Baxter at his presen address: Laboratory of Neuropsychology, National Institute of Mental Health, Building 49, Room 1B80, Bethesda, MD 20892.

Copyright (C) 1997 Society for Neuroscience $0270-6474 / 97 / 175230-07 \$ 05.00 / 0$
}

forebrain lesions (Chiba et al., 1994; Muir et al., 1994; Voytko et al., 1994) also is apparent after selective cholinergic lesions of the basal forebrain (Chiba et al., 1995, 1997; J. J. Waite, personal communication). In contrast, selective destruction of septohippocampal cholinergic projections from the medial septum/vertical limb of the diagonal band (MS/VDB) mainly spares learning and memory abilities that are disrupted by less selective neurotoxic lesions (Berger-Sweeney et al., 1994; Torres et al., 1994; Baxter et al., 1995a, 1996). Hence, the specific function of cholinergic projections of the MS/VDB remains unclear. The possibility that these neurons may be involved in attentional function, like cholinergic neurons in more caudal regions of the basal forebrain, was the focus of the current investigation.

Lesions of the hippocampus disrupt latent inhibition, a phenomenon in which associative learning about a conditioned stimulus (CS) is retarded after it is preexposed in the absence of reward (Ackil et al., 1969; Solomon and Moore, 1975; Kaye and Pearce, 1987; Han et al., 1995). Neurotoxic lesions of the hippocampus also block reductions in processing of a CS that consistently predicts another event (Han et al., 1995). Hence, one role of the hippocampus in associative learning seems to be the reduction of attention to stimuli that are behaviorally irrelevant or for which the behavioral consequences are known. Similarly, electrolytic lesions of the medial septum, damaging cholinergic and noncholinergic septohippocampal projections, also impair latent inhibition (Weiss et al., 1974). This finding raises the possibility that cholinergic projections to the hippocampus also may be involved in reducing attention to conditioned stimuli.

The present experiments were designed to determine whether cholinergic basal forebrain projections to the hippocampus also are involved in regulation of decreases in attentional processing 
within an associative learning framework. The effects of selective cholinergic lesions of septohippocampal cholinergic projections from the MS/VDB on attentional processing were examined in a within-subjects latent inhibition procedure (Experiment 1), and in a serial conditioning procedure in which the predictive relationship of a CS with a subsequent event is manipulated (Experiment 2). In both cases reduced attentional processing of a CS was manifested in a reduction in its ability to enter into new learning.

Portions of the research reported in this article have appeared previously in abstract form (Baxter et al., 1995b).

\section{EXPERIMENT 1}

Experiment 1 was designed to test the hypothesis that removal of the cholinergic projections from the MS/VDB to the hippocampus would produce a deficit in latent inhibition similar to that observed after neurotoxic hippocampal lesions (Han et al., 1995). In this experiment rats with MS/VDB cholinergic lesions (or a control surgery) received presentations of one of two visual CSs, in the absence of food. After this preexposure phase both CSs were paired individually with food. Slower acquisition of conditioned responding to the preexposed CS than to the novel CS would demonstrate latent inhibition.

\section{Materials and Methods}

Subjects. Male Long-Evans rats $(n=19 ; 2-3$ months old at the time of surgery) were obtained from Charles River Laboratories (Raleigh, NC). Starting 2 weeks after surgery, these rats underwent a series of behavioral tests in a Morris water maze, as reported elsewhere (Baxter et al., 1995a). The behavioral procedures described in this experiment began 2-4 months after surgery. Before beginning these procedures (but after the completion of water maze testing), the rats were placed on a restricted feeding schedule to reduce their body weights to $85 \%$ of their freefeeding levels. Weights were maintained at this level for the remainder of the experiment.

Surgery. Selective cholinergic lesions of the MS/VDB were made with injections of $192 \mathrm{IgG}$-saporin, as described previously (Baxter et al., 1995a). 192 IgG-saporin (gift of Dr. Ronald Wiley, Veterans Affairs Medical Center, Nashville, TN) was dissolved in sterile PBS at a concentration of $0.375 \mu \mathrm{g} / \mu \mathrm{l}$. Anesthesia was induced with an intraperitoneal injection of pentobarbital (Nembutal, $55 \mathrm{mg} / \mathrm{kg}$ ) and was supplemented as necessary during surgery, either with Nembutal or with methoxyflurane inhalation anesthetic (Metofane). Injections of sterile PBS (control surgeries, $n=7$ ) or 192 IgG-saporin (lesion surgeries, $n=12$ ) were made through a 28 gauge Hamilton syringe at four sites: anteroposterior (AP) $+0.45 \mathrm{~mm}$, mediolateral $(\mathrm{ML}) \pm 0.6 \mathrm{~mm}$, and dorsoventral (DV) -7.8 $\mathrm{mm}$ and $-6.2 \mathrm{~mm}$ relative to Bregma, according to the Paxinos and Watson (1986) atlas. A volume of $0.3 \mu \mathrm{l}$ was injected at the sites at DV $-7.8 \mathrm{~mm}$, and a volume of $0.2 \mu \mathrm{l}$ was injected into the sites at DV -6.2 $\mathrm{mm}$. Injections were made at the rate of $0.05 \mu \mathrm{l} / \mathrm{min}$. The needle was left in place 9 min after each $0.3 \mu \mathrm{l}$ injection and $6 \mathrm{~min}$ after each $0.2 \mu \mathrm{l}$ injection to limit diffusion up the needle track.

Apparatus. Eight individual chambers were used for behavioral testing. Each chamber $(22.9 \times 20.3 \times 20.3 \mathrm{~cm})$ had aluminum front and back walls, clear acrylic sides and top, and a grid floor $(0.48 \mathrm{~cm}$ stainless steel rods spaced $1.9 \mathrm{~cm}$ apart). A dimly illuminated food cup was recessed in the center of one end wall; a $6 \mathrm{~W}$ jeweled panel light that was the source of one visual CS was located $5 \mathrm{~cm}$ above the opening to the recessed food cup. Each experimental chamber was enclosed in a sound-resistant shell with acrylic windows for viewing the rats. A $6 \mathrm{~W}$ (normally off) house light that served as the other visual CS was mounted on the inside wall of the shell, $25 \mathrm{~cm}$ above and behind the experimental chamber, aligned with the end wall that contained the food cup. A speaker, used to present the auditory CS used in Experiment 2, was mounted next to the house light. Ventilation fans provided masking noise $(70 \mathrm{~dB})$, and a $6 \mathrm{~W}$ lamp behind a red lens opposite the house light provided continuous dim background illumination. Two low-light television cameras were mounted $2.1 \mathrm{~m}$ from the experimental chambers so each could include four chambers in its field of view. Videocassette recorders were programmed to record behaviors that occurred during the $10 \mathrm{sec}$ intervals before, during, and after CS presentations.

Behavioral observation procedures. All observations were made from videotapes and paced by auditory signals recorded on the tapes. Observations were made for each rat at $1.25 \mathrm{sec}$ intervals during the $5 \mathrm{sec}$ period immediately before CS presentations and during CS presentations. At each observation one and only one behavior was recorded.

Two broad categories of behavior were scored. Rear behavior (standing on the hind legs with both front legs off the floor, but not grooming) occurs initially as an unconditioned orienting response to visual CSs like those used in these experiments but also is potentiated by pairing of the CS with the unconditioned stimulus (US). Food cup behavior, which included standing motionless in front of the recessed food cup with the head or nose within the recessed area and head-jerk behavior (short, rapid, horizontal, and/or vertical movements of the head) oriented toward the food cup, initially occurs in response to delivery of the food US but rapidly is acquired to CSs paired with food. Because previous data (Holland, 1977, 1984) showed that rear behavior occurs primarily during the first $5 \mathrm{sec}$ period of a $10 \mathrm{sec}$ CS and that food cup behavior occurs primarily during the last $5 \mathrm{sec}$ of those CSs, we report the frequencies of rear behavior during the first half of the $10 \mathrm{sec}$ CS intervals and of food cup behavior during the last half of the CS intervals. It is worth noting that, because these two behaviors occur primarily at different times, there is little competition between them in performance.

The index of behavioral frequency used was a percentage of total behavior, obtained by dividing the frequency of the target behavior in any observation interval by the total number of observations made in that interval. Note that because the number of observations was constant within each observation interval, this measure is an absolute frequency measure, not a relative one. A single primary observer (P.C.H.) scored all of the behavioral data reported in Experiment 1. To assess objectivity, a second observer (P. N. Fielder) also scored the data from several of the test sessions. The two observers agreed on $96 \%$ of 3456 joint observations. Neither observer was aware of the rats' lesion conditions when the data were scored; in addition, during the acquisition test sessions neither observer knew which CS had been preexposed.

In all experiments we examined pre-CS responding rates for possible effects of lesion or behavioral condition. In those cases in which the effects on during-CS and pre-CS responding were both statistically significant, we computed difference scores (subtracting pre-CS responding from during-CS responding) to determine whether effects on behavior during CS presentation could be accounted for by general differences in activity or responding unrelated to CS presentation (reflected in pre-CS response rates).

Training procedures. First, in each of five daily 64 min preexposure sessions, the rats received eight $10 \mathrm{sec}$ presentations of either the panel light or the house light stimulus (counterbalanced within each lesion condition). Next, the rats were trained to eat from the food cups. Sixteen deliveries of two $45 \mathrm{mg}$ food pellets, which served as the US throughout these experiments, were given at random times within a single $64 \mathrm{~min}$ session. Finally, in each of 15 daily 64 min acquisition test sessions, all rats received four $10 \mathrm{sec}$ presentations of the house light, followed immediately by the food US, and four $10 \mathrm{sec}$ presentations of the panel light, also followed immediately by the food US. These trials were presented in randomly intermixed orders, with variable intertrial intervals that averaged 8 min.

Neurobiological analysis. The majority of the rats (6 control, 9 lesion) were decapitated, and choline acetyltransferase (ChAT) activity was determined in the hippocampus to verify the presence of a lesion. A subset of the rats ( 1 control, 3 lesion) was perfused transcardially with fixatives to prepare the brain tissue for immunohistochemical analysis. Sections were immunostained for ChAT and parvalbumin to determine the extent of cholinergic neuron loss and the sparing of noncholinergic neurons at the lesion site. The procedures used for verification of lesions in these subjects are described more fully elsewhere (Baxter et al., 1995a).

\section{Results}

\section{Neurobiological analysis}

As described previously (Baxter et al., 1995a), the 192 IgGsaporin lesions of the MS/VDB produced a dramatic (90\%) reduction in hippocampal ChAT activity (expressed as a percentage of control), mean $\pm \mathrm{SE}$ : control, $100.0 \pm 4.2$, and lesion, $10.1 \pm 0.51 ; t_{(12)}=24.99, p<0.0001$. Immunohistochemical analysis of the lesion site revealed an absence of ChAT-positive neurons, with no apparent loss of parvalbumin-positive (GABAergic) neurons, confirming the selectivity of the lesion 


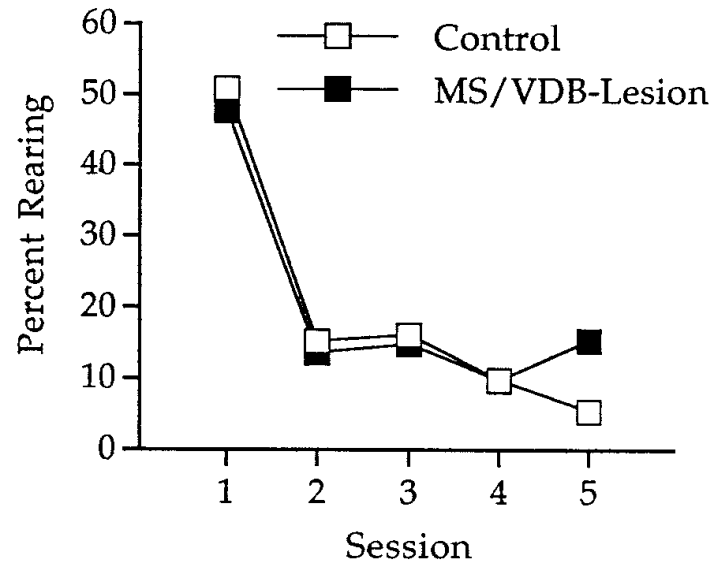

Figure 1. Unconditioned orienting (rearing) to the visual CS during the preexposure phase of Experiment 1. The unconditioned rearing response habituates across sessions of preexposure; this habituation is equivalent in control rats (open squares) and rats with immunolesions of the MS/VDB ( filled squares).

(photomicrographs of material from these same rats appear in Baxter et al., 1995a). One MS/VDB-lesioned rat had normal hippocampal ChAT activity (in the range of the controls) and was excluded from the behavioral analysis. The final numbers of subjects in each group were control, $n=7$ and lesion, $n=11$.

\section{Behavioral data}

Unconditioned rearing behavior to the visual CS during the preexposure phase is presented in Figure 1. It is apparent that rearing to the visual CS decreased over the five preexposure sessions and that the habituation of the unconditioned orienting response did not differ between groups. Data were unavailable for three control rats during the second day of preexposure; ANOVA on levels of rearing from the remaining days revealed a highly significant effect of sessions, $F_{(3,48)}=50.1, p<0.0005$, but no effect of lesion, $F_{(1,16)}=0.05, p=0.83$, or session by lesion interaction, $F_{(3,48)}=$ $1.27, p=0.31$.

The primary data of interest in this experiment are shown in Figure 2. The percentage of conditioned responding (food cup behavior) was analyzed for blocks of three sessions. Conditioning to the preexposed stimulus was diminished, as compared with the novel stimulus in the control rats (reflecting latent inhibition), but conditioning to the novel and preexposed cues occurred at the same level in MS/VDB-lesioned rats. Consistent with this interpretation, parametric ANOVA revealed a significant interaction of lesion and stimulus preexposure, $F_{(1,16)}=8.63, p=0.01$.

Like electrolytic lesions of the medial septum (Weiss et al., 1974) and neurotoxic hippocampal lesions (Han et al., 1995), selective cholinergic lesions of the MS/VDB disrupted the latent inhibition effect. Other factors that could produce a latent inhibition deficit that are unrelated to attentional processing (e.g., failure to habituate to the preexposed CS or increased generalization between the two CSs) cannot account for the present results. Habituation of the unconditioned orienting response to the light proceeded normally in the lesion group. An alteration in generalization between the two stimuli would be expected to produce a level of conditioning in the lesioned rats that was intermediate between the levels of conditioning to the novel and preexposed CSs seen in the control rats; however, the lesioned rats conditioned at levels comparable to the conditioning of the control rats to the novel CS.
A recent experiment that used 192 IgG-saporin lesions of cholinergic projections to the hippocampus reported no effect of these lesions on latent inhibition of a conditioned taste aversion (Dougherty et al., 1996). However, the effects of hippocampal lesions on latent inhibition of conditioned taste aversions are equivocal (McFarland et al., 1978; Reilly et al., 1993; Gallo and Cándido, 1995), which may explain the lack of effect observed in that study. In contrast, the current results are consistent with a disruption in latent inhibition produced by neurotoxic hippocampal lesions in our appetitive within-subject procedure (Han et al., 1995). To examine further the generality of our results, we determined the effect of the removal of cholinergic input to the hippocampus on reductions in attentional processing in a second experiment, in which the loss of attention was not attributable to a stimulus preexposure effect.

\section{EXPERIMENT 2}

To provide additional support for the hypothesis that cholinergic neurons in the MS/VDB are involved in reductions in attentional processing, we tested rats with immunolesions of the MS/VDB in a serial conditioning procedure in which the predictive relationship between two events remains consistent or is shifted from consistent to inconsistent (Wilson et al., 1992). Attention is reduced to a CS that is a consistent predictor of another event (Pearce and Hall, 1980); hippocampal lesions disrupt the decrement in CS processing that occurs in this conditioning procedure (Han et al., 1995).

The conditioning procedure is outlined in Table 1. Control (CTL) and MS/VDB-lesioned (MS/VDB) rats were assigned randomly to either a consistent or shifted training condition, denoting the manipulation of the predictive relationship between the two CSs in one phase of the serial conditioning procedure. This resulted in four groups: CTL-Consistent, CTL-Shift, MS/ VDB-Consistent, MS/VDB-Shift. The procedure included three phases. In phase 1, all rats received presentations of a light CS, followed by a tone $\mathrm{CS}$. The tone was followed by food reinforcement (the US) on $50 \%$ of the trials. This partial reinforcement procedure results in the rapid development of conditioned responding to the tone (because of the temporal contiguity of this CS with the food US). The light does not develop significant conditioned responding because of the poor temporal relationship with the US. More importantly, the light consistently predicts the tone during phase 1 , resulting in decreased attention to the light (Pearce and Hall, 1980).

During phase 2, rats in the Consistent group continued to receive light $\rightarrow$ tone $\rightarrow$ food and light $\rightarrow$ tone $\rightarrow$ nothing trials. Rats in the Shift group also received light $\rightarrow$ tone $\rightarrow$ food trials, but the light $\rightarrow$ tone $\rightarrow$ nothing trials were replaced by light-alone trials. Although this procedure maintains the light-food relationship established in phase 1 and rats experience the same number of light presentations as in the Consistent condition, it makes the light an inconsistent predictor of the tone. This shift in the predictive value of the light restores attention to the light in the Shift group (Wilson et al., 1992). More importantly for this experiment, reduced levels of attention to the light should be maintained in the rats in the Consistent group, because the light maintained its predictive relationship with the tone.

Attention to the light was assessed in phase 3 by pairing the light directly with food. Levels of attention to the light are reflected in the rate of conditioning that occurs to the light in phase 3 . Normally, rats in the Consistent condition show reduced conditioning to the light relative to rats in the Shift condition (Wilson 

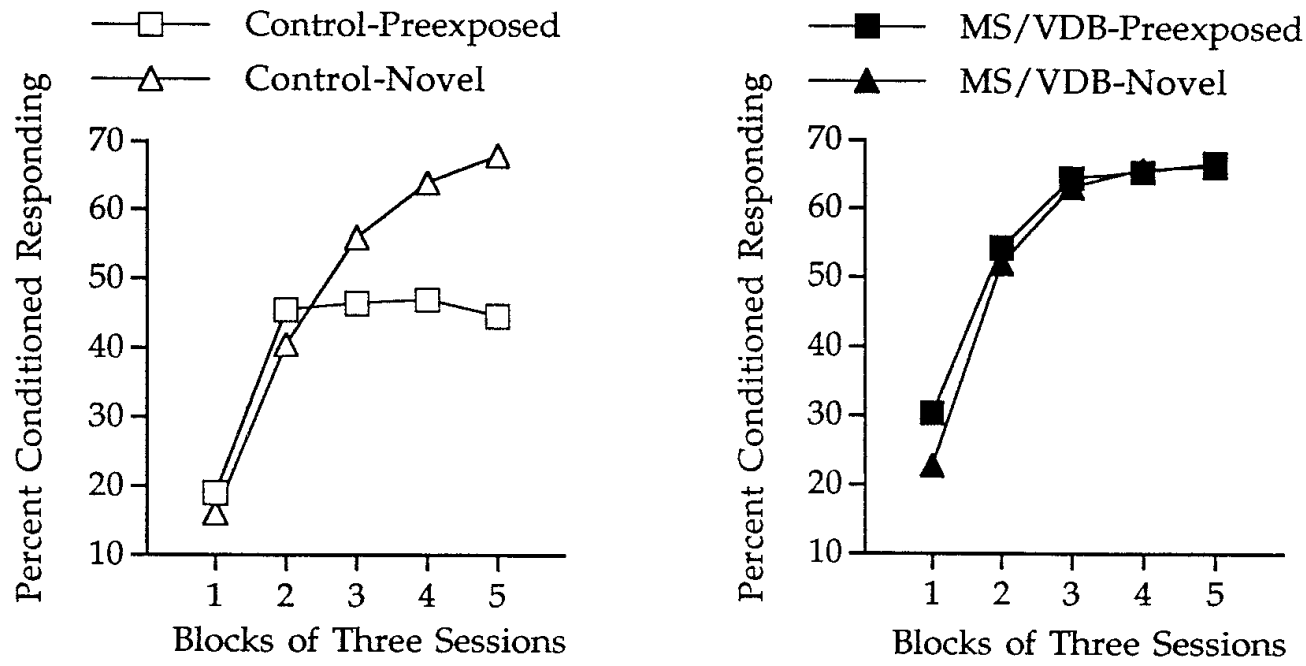

Figure 2. Acquisition of conditioned responding (food cup behavior) to the preexposed and novel CSs in the conditioning phase of Experiment 1. Control rats (left) develop greater conditioning to the novel CS (open triangles), as compared with the preexposed CS (open squares), indicative of latent inhibition. In contrast, rats with immunolesions of the MS/VDB (right) demonstrate equivalent conditioning to the preexposed (filled squares) and novel (filled triangles) stimuli.

Table 1. Serial conditioning procedure used in Experiment 2

Training

condition

Phase 1

Phase 2

Phase 3

Experimental

Consistent light

change in light

Test of

(L)-tone (T)

(L)-tone (T)

learning to

relationship

relationship

light $(\mathrm{L})$

\begin{tabular}{llll}
\hline Consistent & $\mathrm{L} \rightarrow \mathrm{T} \rightarrow$ food & $\mathrm{L} \rightarrow \mathrm{T} \rightarrow$ food & $\mathrm{L} \rightarrow$ food \\
& $\mathrm{L} \rightarrow \mathrm{T}$ & $\mathrm{L} \rightarrow \mathrm{T}$ & \\
Shift & $\mathrm{L} \rightarrow \mathrm{T} \rightarrow$ food & $\mathrm{L} \rightarrow \mathrm{T} \rightarrow$ food & $\mathrm{L} \rightarrow$ food \\
& $\mathrm{L} \rightarrow \mathrm{T}$ & $\mathrm{L}$ &
\end{tabular}

L, Light conditioned stimulus (CS); T, tone CS; $\rightarrow$ signifies serial relation.

et al., 1992). This reduction in conditioning in the Consistent group reflects the loss of attention to the light by virtue of its consistent relationship to the tone. Rats in the Shift condition, although they have received an equivalent number of exposures to the light, show greater conditioning because of the restoration of attention to the light in the Shift condition. The effect of interest in this experiment is that of MS/VDB cholinergic lesions on the reduction in attention to the light that occurs in the Consistent training condition; if these lesions disrupt decrements in attention, then the rate of conditioning of MS/VDB-Consistent rats in phase 3 should be greater than that of the intact rats in that training condition.

\section{Materials and Methods}

Surgery. Surgical procedures were identical to those in Experiment 1, except that $192 \mathrm{IgG}$-saporin was obtained from Chemicon International (Temecula, CA) and was dissolved in sterile PBS at a concentration of $0.506 \mu \mathrm{g} / \mu \mathrm{l}$. Pilot experiments in our laboratory indicated that this concentration of immunotoxin produced lesions of similar extent and specificity to those in Experiment 1.

Subjects, apparatus, and behavioral observation procedures. Experimentally naive male Long-Evans rats $(n=57 ; 275-300 \mathrm{gm}$ at the beginning of the experiment) were obtained from Charles River Laboratories and housed in a similar manner, as in Experiment 1. After $14 \mathrm{~d}$ of postoperative recovery, they were placed on a restricted feeding schedule, as described in Experiment 1. The apparatus and behavioral observation procedures were the same as those used in Experiment 1, except that in this experiment a photo beam placed across the front of the food cup recorded the percentage of time during the CS presentation (and pre-CS period) the rat's head was located in the food cup.

Training procedures. First the rats were trained to eat from the food cups, as in Experiment 1. Then, all rats received 10 daily 64 min phase 1 conditioning sessions. In each of those sessions, four reinforced and four nonreinforced light-tone serial compound CSs were presented, randomly intermixed, with variable intertrial intervals that averaged $8 \mathrm{~min}$. The serial compound consisted of a $10 \mathrm{sec}$ illumination of the panel light, followed immediately by a $10 \mathrm{sec}$ presentation of a $78 \mathrm{~dB}, 1500 \mathrm{~Hz}$ tone. On reinforced trials the tone was followed immediately by two $45 \mathrm{mg}$ food pellets.

In phase 2, the lesioned rats in group MS/VDB-Consistent and the unlesioned rats in group CTL-Consistent received 10 daily sessions identical to those given in phase 1 . In each of the 10 daily 64 min phase 2 sessions, the lesioned rats in group MS/VDB-Shift and the unlesioned rats in group CTL-Shift received four light $\rightarrow$ tone $\rightarrow$ food trials like those given in phase 1 , intermixed with four $10 \mathrm{sec}$ presentations of the panel light alone. As in phase 1 , the intertrial intervals were variable and averaged $8 \mathrm{~min}$.

All rats then received five 64 min daily phase 3 test sessions. In each of those sessions, eight $10 \mathrm{sec}$ illuminations of the panel light were followed by the two-pellet food US. Again, the intertrial intervals were variable and averaged 8 min.

Neurobiological analysis. At the completion of behavioral testing, rats were decapitated and the brains were microdissected rapidly on a chilled glass plate. The hippocampi were processed for ChAT activity to verify the presence of a lesion, essentially as described for Experiment 1, except that $\left[{ }^{3} \mathrm{H}\right]$ acetylcoenzyme A was used as the radioligand.

\section{Results}

\section{Neurobiological analysis}

A number of subjects were excluded because of incomplete lesions (levels of hippocampal ChAT activity within the range of the control rats). The final number of subjects in each condition was CTL-Consistent, $n=10$; CTL-Shift, $n=13$; MS/VDBConsistent, $n=9$; and MS/VDB-Shift, $n=14$. After this exclusion of subjects with incomplete lesions, levels (mean $\pm \mathrm{SE}$ ) of hippocampal ChAT activity (means of left and right hippocampus, percentage of control) for each group were CTL, $100.0 \pm 5.9$, and MS/VDB, $28.2 \pm 2.7$. The reduction of ChAT activity by the MS/VDB immunolesion was highly significant $\left(t_{(44)}=11.0, p<\right.$ $0.0005)$. 
Table 2. Summary data (percentage of time in food cup) from phases 1 and 2 of Experiment 2

\begin{tabular}{lcccccccc} 
& \multicolumn{3}{c}{$\begin{array}{l}\text { Final two sessions of } \\
\text { phase 1 }\end{array}$} & & \multicolumn{3}{c}{$\begin{array}{l}\text { Final two sessions of } \\
\text { phase 2 }\end{array}$} \\
\cline { 2 - 4 } Group & PreCS & Light & Tone & & PreCS & Light & Tone \\
\hline CTL-Consistent & 8.6 & 7.2 & 34.0 & & 11.6 & 11.3 & 46.2 \\
CTL-Shift & 15.4 & 11.4 & 43.5 & & 13.7 & 17.3 & 58.0 \\
MS/VDB-Consistent & 17.9 & 14.1 & 50.7 & & 23.2 & 18.3 & 62.0 \\
MS/VDB-Shift & 18.1 & 15.4 & 55.3 & & 17.6 & 23.4 & 74.4 \\
\hline
\end{tabular}

\section{Behavioral data}

Summary data from the final two sessions of phases 1 and 2 [percentage of conditioned responding (food cup response) during the last half of CS (light or tone) presentation] are presented in Table 2. There was a significant effect of Shift group on responding to the light in phase $1, F_{(1,42)}=6.94, p=0.012$. This result was unexpected because, at this point in the training procedure, shifted and consistent rats had been treated identically. This difference likely is attributable to chance variation; levels of responding to the light were uniformly low, and this difference was not apparent by the last two sessions of phase 1 (comparison of Shift and Consistent groups on last two sessions, $t_{(44)}=-0.79$, $p=0.43)$. There was no effect of session on conditioned responding to the light in phase $1, F_{(9,378)}<1, p>0.50$. There was also no effect of lesion, shift condition, or session on conditioned responding to the light in phase 2 .

Conditioned responding to the tone increased across sessions in phase $1, F_{(9,378)}=16.78, p<0.0005$. A lesion effect on responding to the tone in phase 1 was statistically significant, $F_{(1,42)}=5.51$, $p=0.024$; the session by lesion interaction was also significant, $F_{(9,378)}=3.17, p=0.001$. The lesion groups developed conditioning to the tone slightly more rapidly and at higher levels than the control rats; however, this effect was marginal by the last two sessions $\left(t_{(44)}=-1.78, p=0.08\right)$. Conditioned responding to the tone continued to increase across sessions in phase $2, F_{(9,378)}=$ 8.39, $p<0.0005$. There was a significant effect of lesion on conditioned responding to the tone, $F_{(1,42)}=4.28, p=0.045$. However, there was also a significant effect of lesion on pre-CS responding during phase $2, F_{(1,42)}=6.70, p=0.013$. When difference scores were calculated, subtracting pre-CS responding from responding during the tone, the effect of lesion on responding to the tone was no longer significant, $F_{(1,42)}=1.52, p=0.22$. This suggests that, although lesioned rats tended to show greater levels of conditioned responding in phase 2, this difference could be accounted for by differences in overall levels of activity and responding, unrelated to specific responses to CS presentation, during the phase 2 trials.

The primary data of interest in this experiment, conditioned responding to the light in phase 3, are shown in Figure 3. All groups increased responding to the light across sessions in phase 3 , indicated by a main effect of session, $F_{(4,168)}=37.11, p<$ 0.0005 . As predicted, the MS/VDB-Consistent rats acquired conditioning more rapidly, eventually responding at much higher levels than CTL-Consistent rats. This outcome indicates that MS/VDB-lesioned rats did not lose attention to the light in phases 1 and 2, despite its consistent relationship with the tone. MS/ VDB-Shift and CTL-Shift rats responded at similar levels during phase 3. An interaction of session, lesion, and shift was statistically significant, $F_{(4,168)}=2.77, p=0.029$. This interaction was specific
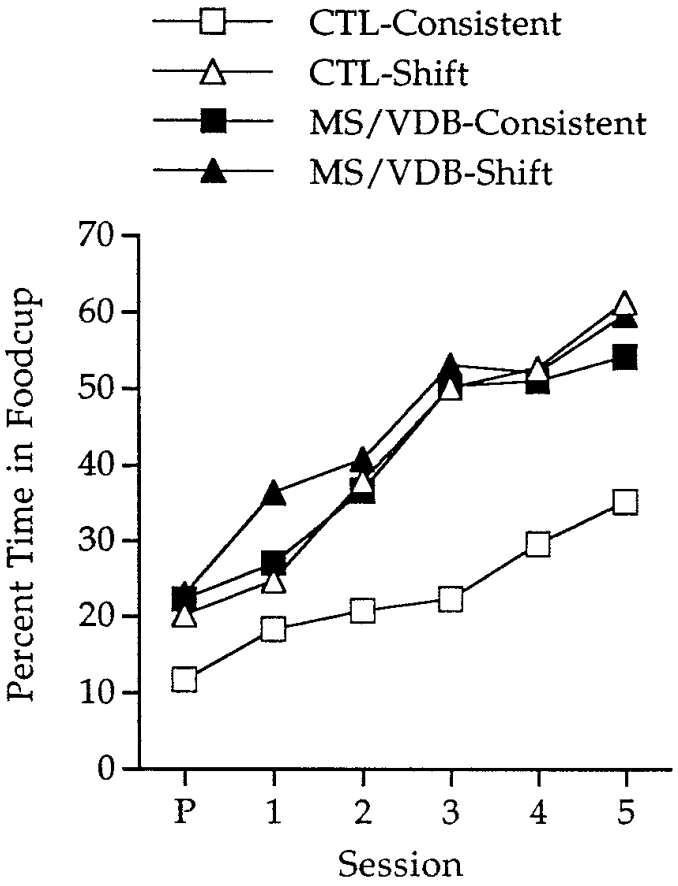

Figure 3. Acquisition of conditioned responding (percentage of time in food cup) during the five sessions of phase 3 in Experiment 2. Responding to the light during the final session of phase 2 is included for comparison $(P)$. Control rats $(C T L$; open symbols $)$ in the Shift condition demonstrate greater conditioning relative to rats in the Consistent condition. In contrast, rats with immunolesions of the MS/VDB (MS/VDB; closed symbols) in the Consistent and Shift conditions show equivalent levels of conditioning, at the level of the CTL-Shift rats.

to responses to the CS and was not apparent in the pre-CS data. Analysis of simple main effects (testing the significance of the lesion $\times$ shift interaction on each of the five sessions of testing; Howell, 1987) revealed a significant lesion $\times$ shift interaction on sessions 3, 4, and 5: $F_{(1, \sim 108)}=7.14, p=0.009 ; F_{(1, \sim 104)}=5.20$, $p=0.025$; and $F_{(1, \sim 111)}=4.92, p=0.029$, respectively, but not on sessions 1 or $2: F_{(1, \sim 147)}=0.13, p=0.72$; and $F_{(1, \sim 120)}=2.13$, $p=0.15$, respectively.

The effects of MS/VDB cholinergic lesions on performance of consistently trained rats in this serial conditioning procedure are qualitatively similar to those of hippocampal lesions: increased performance in phase 3 conditioning, as compared with controls. This suggests a similar disruption of decremental CS processing after MS/VDB lesions. It was not clear whether incremental processing was also disrupted after MS/VDB lesions. The absence of a shift effect in the MS/VDB groups could indicate that reduction of attention to a CS is required before a subsequent manipulation of its predictive power will increment attention to that CS. However, in rats with neurotoxic hippocampal lesions that also disrupted decremental CS processing, conditioning was enhanced in shifted rats, as compared with consistent rats (Han et al., 1995). It is possible that conditioning was already at ceiling levels in the MS/VDB rats, making it impossible to observe an additional effect of the shift. In any case, the behavior of the MS/VDB-Consistent rats confirms the basic prediction of this experiment: that a decrement in attention associated with a consistent predictive relationship also will be disrupted after removal of hippocampal cholinergic input. 


\section{DISCUSSION}

The present results indicate that, like lesions of the hippocampus (Han et al., 1995), selective lesions of cholinergic neurons in the MS/VDB disrupted losses in the ability of CSs to participate in new learning that normally occurs in many associative learning procedures. Both latent inhibition (Experiment 1) and losses in the rate of new learning to a consistently predictive CS in a serial conditioning task (Experiment 2) were impaired by these lesions. This specific impairment in decremental attentional processing stands in contrast to the relative inability of these lesions to impair learning and memory in a variety of test procedures (BergerSweeney et al., 1994; Torres et al., 1994; Baxter et al., 1995a; McMahan et al., 1997). It is interesting to note that these same rats that showed a disruption in latent inhibition in Experiment 1 showed no spatial learning deficit whatsoever in the Morris water maze task (Baxter et al., 1995a), which also is sensitive to neurotoxic hippocampal lesions (Morris et al., 1982; Gallagher and Holland, 1992) and less selective neurotoxic lesions of the MS/ VDB (Hagan et al., 1988; Marston et al., 1993). This dissociation might suggest that there are psychologically dissociable functions of the hippocampus, one that is dependent on cholinergic input and one that is not. Comparisons between the behavioral effects of hippocampal lesions and removal of hippocampal cholinergic input therefore might shed light on the specific psychological functions controlled by the hippocampus.

The correspondence between effects of immunolesions of the MS/VDB and neurotoxic hippocampal lesions on CS processing suggests that cholinergic projections from the MS/VDB to the hippocampus are involved in regulating certain attentional functions of the hippocampus. One possible mechanism might be via an effect on the amplitude of hippocampal theta rhythm; selective removal of hippocampal cholinergic input does not disrupt the rate of hippocampal theta but does decrease its amplitude dramatically (Jenkins et al., 1993; Lee et al., 1994; Bassant et al., 1995). By this view, cholinergic projections from the MS/VDB to the hippocampus modulate the processing of information that occurs in the hippocampus itself.

Other research with these same tasks has indicated that another system, which includes the central nucleus of the amygdala (CN) and its projections to the nucleus basalis magnocellularis/substantia innominata (nBM/SI), controls incremental processing independent of decremental processing: lesions of $\mathrm{CN}$ or of cholinergic neurons in the nBM/SI spare decremental processing (e.g., latent inhibition) but eliminate incremental processing (like that produced by the shift in the serial conditioning procedure; Holland and Gallagher, 1993; Chiba et al., 1995). Within this system cholinergic projections from the nBM/SI to neocortex are hypothesized to modulate information processing in the cortex (Holland and Gallagher, 1993; Gallagher and Holland, 1994; Chiba et al., 1995). By analogy, the role of the hippocampus in decremental processing may be like that of $\mathrm{CN}$ in incremental processing; that is, it may regulate processing in cortical targets of the MS/VDB (e.g., cingulate cortex) (Amaral and Kurz, 1985; Gaykema et al., 1990) via its efferent projections to the septum (Swanson, 1977; Swanson and Cowan, 1977; Gaykema et al., 1991). This still would account for similar effects of hippocampal lesions and immunolesions of the MS/VDB on attentional processing. This hypothesis could be tested by determining whether infusions of 192 IgGsaporin into cingulate cortex (removing cholinergic projections to that cortical area only) reproduce the effects of immunolesions of the MS/VDB on attentional processing. Such an anatomical framework would suggest that information about the associative history of stimuli resides in subcortical structures (e.g., the hippocampus and amygdala) and that these structures direct cortical information processing (i.e., regulate attention) via projections onto specific subsets of cholinergic neurons in the basal forebrain.

The present finding that removal of cholinergic projections to the hippocampus disrupts one aspect of attention, namely the ability to reduce the ability of CSs to enter into new learning, raises the possibility that cholinergic neurons in the MS/VDB may be involved in other aspects of attentional processing, for example, divided attention or vigilance (for review, see Muir, 1996). However, the finding that these lesions do not produce a generalized learning impairment (Berger-Sweeney et al., 1994; Torres et al., 1994; Baxter et al., 1995a) suggests that the impairment of attention produced by removal of hippocampal cholinergic input may be relatively specific to reductions in CS processing produced by particular experimental histories. Future experiments will examine the potential involvement of septohippocampal cholinergic projections in different aspects of attentional processing and the conditions under which these projections are engaged during learning.

Previous studies have indicated that selective destruction of basal forebrain cholinergic neurons spares cognitive abilities (such as spatial learning) once thought to depend at least partially on normal functioning of these neurons (Berger-Sweeney et al., 1994; Torres et al., 1994; Baxter et al., 1995a, 1996; Baxter and Gallagher, 1996). The present results, taken together with other data (Muir et al., 1994; Chiba et al., 1995, 1997; McGaughy et al., 1996), indicate that specific deficits in attentional processing result from selective destruction of basal forebrain cholinergic neurons. These data support the hypothesis, discussed in recent reviews (Lawrence and Sahakian, 1995; Baxter and Gallagher, 1997), that impairments in attentional processing in these disorders (rather than impairments in memory) are linked more closely to degeneration of basal forebrain cholinergic neurons and that this attentional dysfunction (rather than memory dysfunction) might be more responsive to pharmacological therapies targeting the cholinergic system. Importantly, the results of the present experiment broaden this hypothesis to include a role for septohippocampal cholinergic projections in the regulation of attention, implicating both rostral and caudal regions of the basal forebrain in attentional function.

\section{REFERENCES}

Ackil JE, Mellgren RL, Halgren C, Frommer GP (1969) Effects of CS preexposures on avoidance learning in rats with hippocampal lesions. J Comp Physiol Psychol 69:739-747.

Amaral DG, Kurz J (1985) An analysis of the origins of the cholinergic and noncholinergic septal projections to the hippocampal formation of the rat. J Comp Neurol 240:37-59.

Bassant MH, Apartis E, Jazat-Poindessous FR, Wiley RG, Lamour YA (1995) Selective immunolesion of the basal forebrain cholinergic neurons: effects on hippocampal activity during sleep and wakefulness in the rat. Neurodegeneration 4:61-70.

Baxter MG, Gallagher M (1996) Intact spatial learning in both young and aged rats following selective removal of hippocampal cholinergic input. Behav Neurosci 110:460-467.

Baxter MG, Gallagher M (1997) Cognitive effects of selective loss of basal forebrain cholinergic neurons: implications for cholinergic therapies of Alzheimer's disease. In: Pharmacological treatment of Alzheimer's disease: molecular and neurobiological foundations (Brioni JD, Decker MW, eds), pp 87-103. New York: Wiley.

Baxter MG, Bucci DJ, Gorman LK, Wiley RG, Gallagher M (1995a) Selective immunotoxic lesions of basal forebrain cholinergic cells: effects on learning and memory in rats. Behav Neurosci 109:714-722.

Baxter MG, Gallagher M, Holland PC (1995b) Disruption of decremen- 
tal attentional processing by selective removal of hippocampal cholinergic input. Soc Neurosci Abstr 21:935.

Baxter MG, Bucci DJ, Sobel TJ, Williams MJ, Gorman LK, Gallagher M (1996) Intact spatial learning following lesions of basal forebrain cholinergic neurons. NeuroReport 7:1417-1420.

Berger-Sweeney J, Heckers S, Mesulam M-M, Wiley RG, Lappi DA, Sharma M (1994) Differential effects on spatial navigation of immunotoxin-induced cholinergic lesions of the medial septal area and nucleus basalis magnocellularis. J Neurosci 14:4507-4519.

Chiba AA, Han J-S, Holland PC, Gallagher M (1994) Substantia innominata lesions impair incremental attentional processing in a Pavlovian conditioning paradigm. Soc Neurosci Abstr 20:1215.

Chiba AA, Bucci DJ, Holland PC, Gallagher M (1995) Basal forebrain cholinergic lesions disrupt increments but not decrements in conditioned stimulus processing. J Neurosci 15:7315-7322.

Chiba AA, Bushnell PJ, Oshiro WM, Gallagher M (1997) Selective removal of cholinergic neurons in the basal forebrain alters cued target detection in rats. NeuroReport, in press.

Decker MW, Radek RJ, Majchrzak MJ, Anderson DJ (1992) Differential effects of medial septal lesions on spatial memory tasks. Psychobiology 20:9-17.

Dougherty KD, Salat D, Walsh TJ (1996) Intraseptal injection of the cholinergic immunotoxin 192 IgG-saporin fails to disrupt latent inhibition in a conditioned taste aversion paradigm. Brain Res 736:260-269.

Gallagher M, Holland PC (1992) Preserved configural learning and spatial learning impairment in rats with hippocampal damage. Hippocampus 2:81-88.

Gallagher M, Holland PC (1994) The amygdala complex: multiple roles in associative learning and attention. Proc Natl Acad Sci USA 91:11771-11776.

Gallo M, Cándido A (1995) Dorsal hippocampal lesions impair blocking but not latent inhibition of taste aversion learning in rats. Behav Neurosci 109:413-425.

Gaykema RPA, Luiten PGM, Nyakas C, Traber J (1990) Cortical projection patterns of the medial septum-diagonal band complex. J Comp Neurol 293:103-124.

Gaykema RPA, van der Kuil J, Hersh LB, Luiten PGM (1991) Patterns of direct projections from the hippocampus to the medial septumdiagonal band complex: anterograde tracing with Phaseolus vulgaris leucoagglutinin combined with immunohistochemistry of choline acetyltransferase. Neuroscience 43:349-360.

Hagan JJ, Salamone JD, Simpson J, Iversen SD, Morris RGM (1988) Place navigation in rats is impaired by lesions of medial septum and diagonal band but not nucleus basalis magnocellularis. Behav Brain Res 27:9-20.

Han J-S, Gallagher M, Holland PC (1995) Hippocampal lesions disrupt decrements but not increments in conditioned stimulus processing. J Neurosci 15:7323-7329.

Heckers S, Ohtake T, Wiley RG, Lappi DA, Geula C, Mesulam M-M (1994) Complete and selective cholinergic denervation of rat neocortex and hippocampus but not amygdala by an immunotoxin against the p75 NGF receptor. J Neurosci 14:1271-1289.

Holland PC (1977) Conditioned stimulus as a determinant of the form of the Pavlovian conditioned response. J Exp Psychol Anim Behav Processes 3:77-104.

Holland PC (1984) Origins of behavior in Pavlovian conditioning. In: The psychology of learning and motivation, Vol 18 (Bower GH, ed), pp 129-174. Orlando, FL: Academic.

Holland PC, Gallagher M (1993) Amygdala central nucleus lesions disrupt increments, but not decrements, in conditioned stimulus processing. Behav Neurosci 107:246-253.

Howell DC (1987) Statistical methods for psychology, 2nd Ed. Boston: PWS-Kent.

Jenkins J, Heckers S, Mesulam M, Wiley RG, Berger-Sweeney J (1993) Effects of 192 IgG-saporin-induced medial septal lesions on hippocampal activity in free-moving rats. Soc Neurosci Abstr 19:412.

Kaye H, Pearce JM (1987) Hippocampal lesions attenuate latent inhibition and the decline of the orienting response in rats. Q J Exp Psychol 39[B]:107-125.

Kelsey JE, Landry BA (1988) Medial septal lesions disrupt spatial mapping ability in rats. Behav Neurosci 102:289-293.

Kelsey JE, Vargas H (1993) Medial septal lesions disrupt spatial, but not nonspatial, working memory in rats. Behav Neurosci 107:565-574.
Lawrence AD, Sahakian BJ (1995) Alzheimer disease, attention, and the cholinergic system. Alzheimer Dis Assoc Disord 9[Suppl 2]:43-49.

Lee MG, Chrobak JJ, Sik A, Wiley RG, Buzsáki G (1994) Hippocampal theta activity following selective lesion of the septal cholinergic system. Neuroscience 62:1033-1047.

Marston HM, Everitt BJ, Robbins TW (1993) Comparative effects of excitotoxic lesions of the hippocampus and septum/diagonal band on conditional visual discrimination and spatial learning. Neuropsychologia 31:1099-1118.

McFarland DJ, Kostas J, Drew WG (1978) Dorsal hippocampal lesions: effects of preconditioning CS exposure on flavor aversion. Behav Biol 22:398-404

McGaughy J, Kaiser T, Sarter M (1996) Behavioral vigilance following infusions of $192 \mathrm{IgG}$-saporin into the basal forebrain: selectivity of the behavioral impairment and relation to cortical AChE-positive fiber density. Behav Neurosci 110:247-265.

McMahan RW, Sobel TJ, Baxter MG (1997) Selective immunolesions of hippocampal cholinergic input fail to impair spatial working memory. Hippocampus 7:130-136.

Morris RGM, Garrud P, Rawlins JNP, O’Keefe J (1982) Place navigation impaired in rats with hippocampal lesions. Nature 297:681-683.

Muir JL (1996) Attention and stimulus processing in the rat. Cognit Brain Res 3:215-225.

Muir JL, Robbins TW, Everitt BJ (1992) Disruptive effects of muscimol infused into the basal forebrain on conditional discrimination and visual attention: differential interactions with cholinergic mechanisms. Psychopharmacology (Berl) 107:541-550.

Muir JL, Everitt BJ, Robbins TW (1994) AMPA-induced excitotoxic lesions of the basal forebrain: a significant role for the cortical cholinergic system in attentional function. J Neurosci 14:2313-2326.

Paxinos G, Watson C (1986) The rat brain in stereotaxic coordinates, 2nd Ed. San Diego: Academic.

Pearce JM, Hall G (1980) A model for Pavlovian learning: variations in the effectiveness of conditioned but not of unconditioned stimuli. Psychol Rev 87:532-552.

Reilly S, Harley C, Revusky S (1993) Ibotenate lesions of the hippocampus enhance latent inhibition in conditioned taste aversion and increase resistance to extinction in conditioned taste preference. Behav Neurosci 107:996-1004.

Robbins TW, Everitt BJ, Marston HM, Wilkinson J, Jones GH, Page KJ (1989) Comparative effects of ibotenic acid- and quisqualic acidinduced lesions of the substantia innominata on attentional function in the rat: further implications for the role of the cholinergic neurons of the nucleus basalis in cognitive processes. Behav Brain Res 35:221-240.

Solomon PR, Moore JW (1975) Latent inhibition and stimulus generalization of the classically conditioned nictitating membrane response in rabbits (Oryctolagus cuniculus) following dorsal hippocampal ablation. J Comp Physiol Psychol 89:1192-1203.

Swanson LW (1977) The anatomical organization of septo-hippocampal projections. Ciba Found Symp 58:25-48.

Swanson LW, Cowan WM (1977) An autoradiographic study of the organization of the efferent connections of the hippocampal formation in the rat. J Comp Neurol 172:49-84.

Torres EM, Perry TA, Blokland A, Wilkinson LS, Wiley RG, Lappi DA, Dunnett SB (1994) Behavioural, histochemical, and biochemical consequences of selective immunolesions in discrete regions of the basal forebrain cholinergic system. Neuroscience 63:95-122.

Voytko ML, Olton DS, Richardson RT, Gorman LK, Tobin JR, Price DL (1994) Basal forebrain lesions in monkeys disrupt attention but not learning and memory. J Neurosci 14:167-186.

Wainer BH, Mesulam M-M (1990) Ascending cholinergic pathways in the rat brain. In: Brain cholinergic systems (Steriade M, Biesold D, eds), pp 65-119. Oxford: Oxford UP.

Weiss KR, Friedman R, McGregor S (1974) Effects of septal lesions on latent inhibition and habituation of the orienting response in rats. Acta Neurobiol Exp (Warsz) 34:491-504.

Wiley RG, Oeltmann TN, Lappi DA (1991) Immunolesioning: selective destruction of neurons using immunotoxin to rat NGF receptor. Brain Res 562:149-153.

Wilson PN, Boumphrey P, Pearce JM (1992) Restoration of the orienting response to a light by a change in its predictive accuracy. Q J Exp Psychol 44[B]:17-36. 